\title{
A New Species of Eotetranychus Spider Mite (Arachnida: Acari: Tetranychidae) from Tilia (Tiliaceae) in Hokkaido
}

\author{
Shôzô Ehara' ${ }^{1}$ and Tetsuo Gotoh ${ }^{2}$ \\ ${ }^{1}$ Hamasaka 2-15-7, Tottori, 680-0001 Japan \\ E-mail: shozoehama@ncn-t.net \\ ${ }^{2}$ Laboratory of Applied Entomology and Zoology, Faculty of Agriculture, \\ Ibaraki University, Ami, Ibaraki, 300-0393 Japan \\ E-mail: gotoh@mx.ibaraki.ac.jp
}

(Received 21 February 2008; Accepted 1 June 2008)

\begin{abstract}
Eotetranychus tiliaecola Ehara and Gotoh, sp. nov. is described and illustrated from Tilia maximowicziana Shirasawa (Tiliaceae). It was also found to occur on T. japonica (Miq.) Simonkai in Hokkaido, Japan. The aedeagus of this species closely resembles that of E. tsugaruensis Ehara, 1989, but differs in having the distal part strongly sigmoid and its termination more slender, and in the widely concave dorsal margin of the shaft.

Key Words: Acari, Eotetranychus, Hokkaido, Japan, new species, spider mite, Tetranychidae, Tilia.
\end{abstract}

\section{Introduction}

Spider mites of the genus Eotetranychus Oudemans in the subfamily Tetranychinae are characterized by an opisthosoma with transverse striae in the dorsocentral area and 2 pairs of para-anal setae, and by trifurcate empodia (usually except for leg I of the male). These mites are found feeding on the under surface of leaves; summer females of most species are pale green-yellow, while those of the remaining species are pale yellow or reddish. There are approximately 185 known species of Eotetranychus in the world (Bolland et al. 1998; Migeon and Dorkeld 2007), and 22 species have so far been reported from Japan (Ehara 1999; Ehara and Gotoh 2006). In the present paper a new species of this genus is described and illustrated from Tilia maximowicziana Shirasawa in Hokkaido.

\section{Materials and Methods}

The collected mites were preserved in $70 \%$ ethyl alcohol and later mounted in Hoyer's medium on glass slides for examination. Mites were examined under an Olympus BHS compound microscope equipped with phase contrast system. Drawings were made using a camera lucida attached to the microscope.

The setal notations generally follow Lindquist's (1985) system. The measurements are given in micrometers $(\mu \mathrm{m})$; those of the holotype of the new species are shown in parentheses following the mean. The holotype and some of the paratypes of the new species are deposited in the collections of the National Museum of Na- 
ture and Science, Tokyo (NSMT); the remainder of the paratypes are placed in the Kyoto University Museum (KUM).

Eotetranychus tiliaecola Ehara and Gotoh, sp. nov.

[Japanese name: Usinose-akehadani]

(Figs 1-11)

Material examined. Holotype: $\delta$ (NSMT-Ac 12930), Naganuma, Sorachi Prov., Hokkaido, 9-VIII-2006 (T. Gotoh leg.), on Tilia maximowicziana (Tiliaceae). Paratypes: $6{ }^{\star}$ (NSMT-Ac 12931-12934) and 9 9 (NSMT-Ac 12935-12937), same data as holotype; $30^{\circ}$ and 39 (KUM), same data as holotype.

In addition to the type series, the following specimens, all in poor condition, were also examined: $5 \delta^{\circ}$ and 10 \% Ishikari, Ishikari Prov., Hokkaido, 8-VIII-2006 (T. Gotoh leg.), on Tilia japonica (Miq.) Simonkai. These specimens are retained in our collections.

Description. Female. Body pale green-yellow with dark lateral spots. Rostrum reaching distal part of femur I (Fig. 1). Palpus (Fig. 2) with spinneret approximately twice as long as broad; dorsal sensillum (solenidion) slender. Peritreme hooked distally (Fig. 4). Dorsal setae on idiosoma longer than distances between bases of successive setae (Fig. 1). Opisthosomal striae on dorsocentral region transverse. Genital flap with transverse striae; area immediately anterior to flap with longitudinal striae.

Numbers of setae and solenidia (in parentheses) on leg segments: coxae 2-2-1-1, trochanters 1-1-1-1, femora 10-7-4-4, genua 5-5-4-4, tibiae 9(1)-8-6-7, tarsi 14(1)+2 dupl.-13(1)+1 dupl.-10(1)-10(1). Tarsus I with 5 tactile setae and 1 solenidion proximal to proximal set of duplex setae (Fig. 5); tarsus II with 3 tactile setae and 1 solenidion proximal to duplex setae (Fig. 6). Empodia consisting of 3 pairs of hairs and 1 minute but distinct mediodorsal spur.

Measurements $(n=10)$. Length of body (including rostrum) 393-454, mean 431; width of body $205-269$, mean 234. Lengths (mean \pm SE) of setae: v2 $64.7 \pm 0.4$, sc1 $125.0 \pm 0.8$, sc2 $83.0 \pm 0.5$, c1 $114.8 \pm 0.6$, c2 $113.1 \pm 1.4$, c3 $104.5 \pm 1.9$, d1 $106.8 \pm 1.5$, d2 109.6 \pm 1.2 , e1 100.1 \pm 1.0 , e2 $100.0 \pm 0.9$, f1 $90.5 \pm 1.0$, f2 $65.1 \pm 0.9$, h1 $59.3 \pm 0.8$.

Male. Color similar to female. Palpus (Fig. 3) with spinneret subconical to nipple-shaped and much shorter than dorsal sensillum. Aedeagus (Figs 9-11) with shaft very broad and strongly downcurved to form conspicuously sigmoid, tapering distal part of aedeagus; termination nearly straight, slender; shaft with dorsal margin widely concave and ventral margin convex posteriorly.

Numbers of setae and solenidia (in parentheses) on leg segments: coxae 2-2-1-1, trochanters 1-1-1-1, femora 10-7-4-4, genua 5-5-4-4, tibiae 9(3)-8-6-7, tarsi 13(3)+ 2 dupl. $-13(1)+1$ dupl.-10(1)-10(1). Tarsus I with 4 tactile setae and 3 solenidia proximal to proximal set of duplex setae (Fig. 7); tarsus II with 3 tactile setae and 1 solenidion proximal to duplex setae (Fig. 8). Empodium I with fine mediodorsal spur and 3 pairs of digits, including stout dorsal and middle pairs and weak ventral pair; empodia II-IV similar to those of female.

Measurements $(n=10)$. Length of body (including rostrum) 300-343, mean 321 (312); width of body 119-142, mean $131(-)$. Lengths (mean \pm SE) of setae: v2 50.3 \pm 0.8 


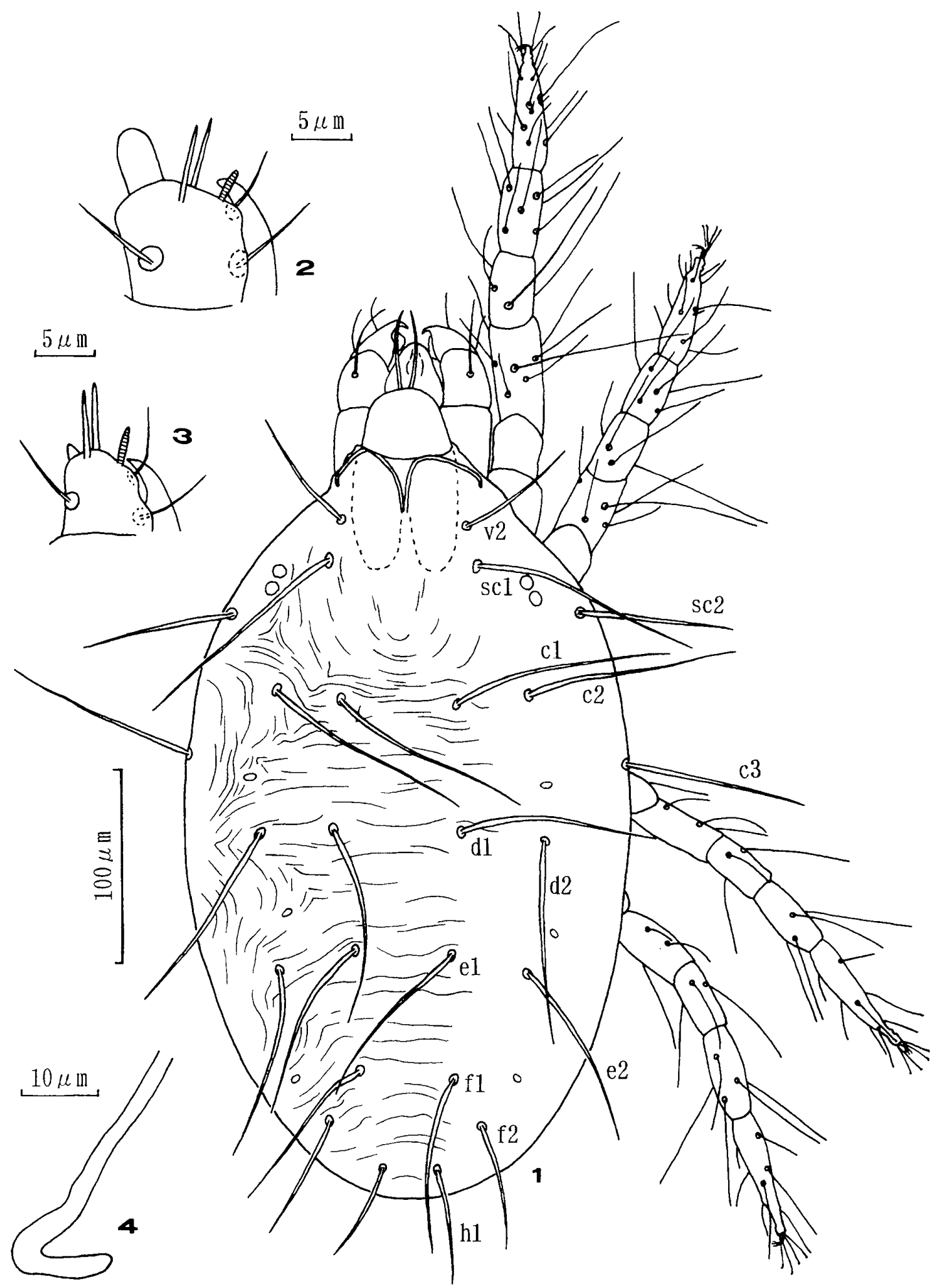

Figs 1-4. Eotetranychus tiliaecola sp. nov. 1, Dorsum (q); 2, distal segment of palpus (q); 3, ditto (ठ); 4, peritreme (ㅇ). 


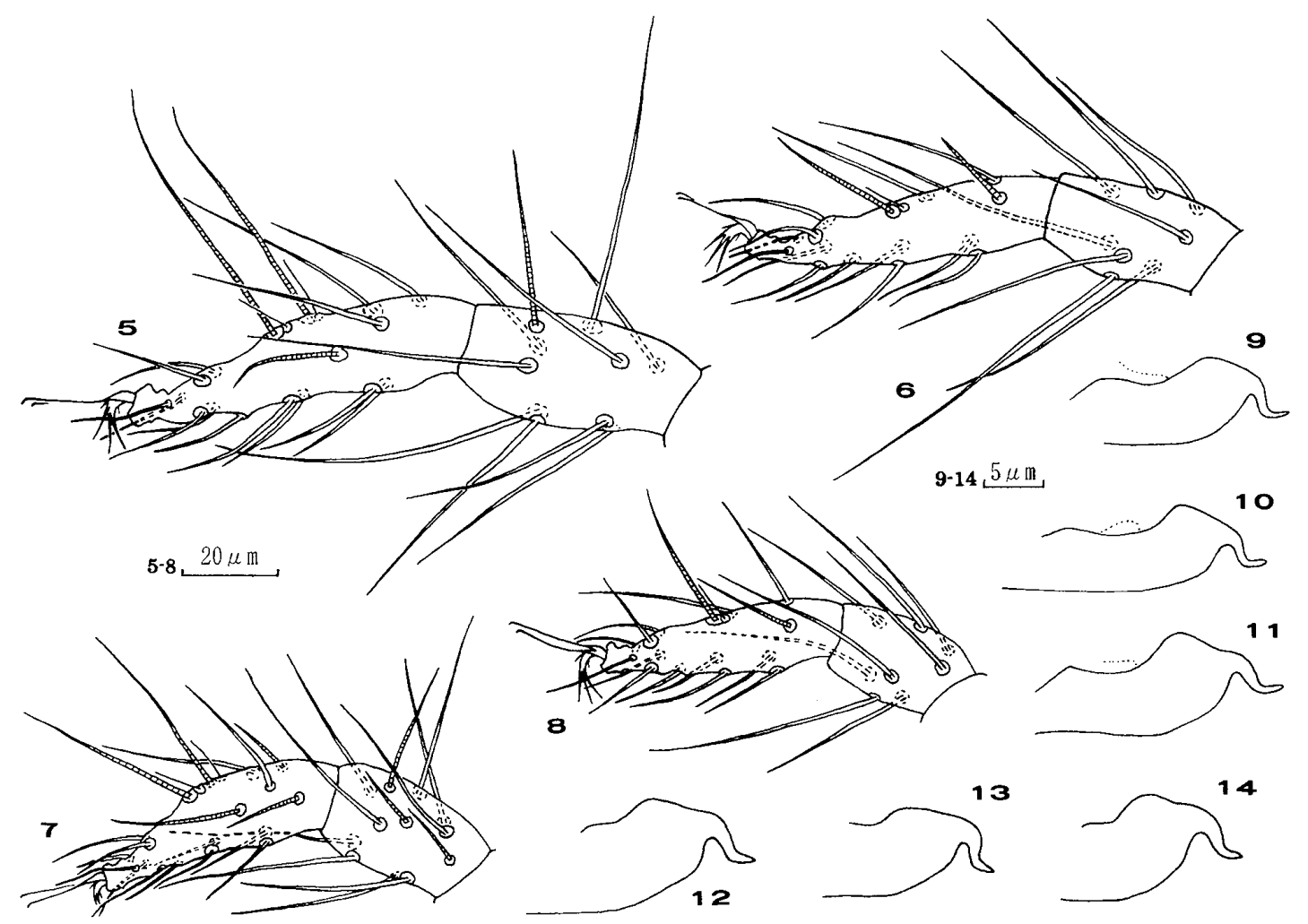

Figs 5-14. Eotetranychus tiliaecola sp. nov. (5-11) and E. tsugaruensis (12-14). 5, Tarsus and tibia I ( $q) ; 6$, tarsus and tibia II ( ()$; 7$, tarsus and tibia I ( $)$ ); 8, tarsus and tibia II ( $)$ ); 9-14, aedeagi (9, holotype; 12-14, after Ehara 1989).

(50.6), sc1 89.2 \pm 1.2 (91.6), sc2 65.2 \pm 1.1 (64.8), c1 79.7 \pm 0.8 (77.4), c2 $82.2 \pm 1.0$ (83.3), c3 $76.4 \pm 1.2$ (77.8), d1 72.4 \pm 0.9 (72.3), d2 79.1 \pm 0.8 (75.4), e1 $63.3 \pm 1.0$ (61.4), e2 $69.8 \pm 1.0$

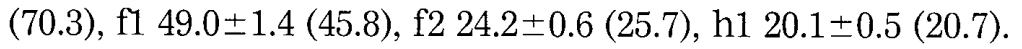

Etymology. The specific name tiliaecola (masculine noun) is derived from the Latin tilia, "linden tree", plus the Latin cola, "inhabitant", and refers to the occurrence of the present mites on linden trees.

Remarks. Eotetranychus tiliaecola sp. nov. is assigned to the E. hicoriae species group. The new species is similar to E. nanningensis Ma and Wang, 1981, E. cyphus Baker and Pritchard, 1960, and E. tsugaruensis Ehara, 1989 in the shape of the aedeagus (cf. Baker and Pritchard 1960; Meyer 1974, 1987; Wang and Ma 1981; Ehara 1989); however, E. nanningensis differs from E. tiliaecola in having the male palpus with no spinneret, and E. cyphus differs from it in having just a minute spinneret. Furthermore, the aedeagus of E. tsugaruensis is distinct from that of the new species in that the distal part of the former is more weakly sigmoid and the dorsal margin of its shaft is slightly concave (Figs 12-14).

\section{Acknowledgement}

We are very grateful to Dr. Y. Hirashima (Professor Emeritus, Kyushu Univer- 
sity) for his valuable advice concerning the zoological nomenclature.

\section{References}

Baker, E. W. and Pritchard, A. E. 1960. The tetranychoid mites of Africa. Hilgardia 29: $455-574$.

Bolland, H. R., Gutierrez, J. and Flechtmann, C. H. W. 1998. World Catalogue of the Spider Mite Family (Acari: Tetranychidae). Koninklijke Brill NV, Leiden, 392 pp.

Ehara, S. 1989. Four new species of spider mites (Acarina: Tetranychidae) from Japan. Proceedings of the Japanese Society of Systematic Zoology 40: 28-38.

Ehara, S. 1999. Revision of the spider mite family Tetranychidae of Japan (Acari, Prostigmata). Species Diversity 4: 63-141.

Ehara, S. and Gotoh, T. 2006. Description of a new Eotetranychus from Japan with notes on two other species (Acari: Prostigmata: Tetranychidae). International Journal of Acarology 32: 39-44.

Lindquist, E. E. 1985. Anatomy, phylogeny and systematics. 1.1.1. External anatomy. Pp. 3-28. In: Helle, W. and Sabelis, M. W. (Eds) Spider Mites. Their Biology, Natural Enemies and Control. Vol. 1A. Elsevier, Amsterdam.

Meyer, M. K. P. (Smith) 1974. A revision of the Tetranychidae of Africa (Acari) with a key to the genera of the world. Entomology Memoir, Department of Agricultural Technical Services, Republic of South Africa 36: 1-291.

Meyer, M. K. P. (Smith) 1987. African Tetranychidae (Acari: Prostigmata)-with reference to the world genera. Entomology Memoir, Department of Agriculture and Water Supply, Republic of South Africa 69: i-iv+1-175.

Migeon, A. and Dorkeld, F. 2007. Spider mites web: a comprehensive database for the Tetranychidae. http://www.montpellier.inra.fr./CBGP/spmweb/ (last accessed May 17 2008).

Wang, H. and Ma, E. 1981. Two new species of Tetranychidae from China (Acarina: Tetranychidae). Zoological Research 2: 327-341. [In Chinese with English summary] 